\title{
WHO warns of risk of Zika virus in Europe
}

\author{
Anne Gulland
}

London

The overall risk of Zika virus transmission in Europe this spring and summer is low to moderate, the World Health Organization has warned, although three countries are at high risk of the disease.

A risk assessment published by WHO's regional office for Europe found a high risk of spread on the Portuguese island of Madeira and in the northeastern Black Sea coast

region - namely, Georgia and the southern part of the Russian Federation. These areas have the Aedes aegypti mosquito, the primary vector for the virus.

However, WHO also warned of a moderate risk of spread in 18 countries, primarily in the Mediterranean basin, where the Aedes albopictus mosquito, a secondary Zika vector, is present. These countries include many popular summer holiday destinations such as France, Greece, Italy, Spain, and Turkey.

Croatia and France witnessed outbreaks of dengue in 2010, and a serious outbreak occurred in Madeira in 2012. Italy had an outbreak of chikungunya in 2007. In Madeira, A aegypti was the main vector, but in the other countries $A$ albopictus was responsible.

Speaking at a press conference, WHO officials emphasised that no Zika virus currently existed in Europe. Colleen Acosta, epidemiologist at WHO's European division of communicable diseases and health security, said, "There is no local Zika virus transmission via mosquitoes at present, although we have seen several cases of sexual transmission. WHO has guidance in terms of practising safe sex."

WHO has not warned travellers to avoid areas with moderate to high risk of transmission, said João Pires, medical officer at WHO's European division of communicable diseases and health security.
But he added, "In case local transmission happens in the summer months we will align our travel advice with WHO guidance. . . Pregnant women are at a high risk of complications from Zika virus, and we stress the importance of personal protection measures." These include wearing insect repellent and covering up to prevent mosquito bites.

Countries with moderate to high likelihood of local Zika virus transmission should strengthen or maintain their vector control activities and improve entomological surveillance, said WHO. Some 36 countries in the European region have a low likelihood or no likelihood of Zika transmission because of the absence of Zika vectors or suitable climatic conditions for their establishment. Pires said that, in these countries, such as the United Kingdom, which has a low risk, travel health clinics must ensure that they can detect cases of Zika virus transmission. A survey of 51 of 53 member states in the region to assess their capacity to deal with Zika found that 41 countries (79\%) had either very good or good capacity to do so. This included low risk countries, such as the UK. WHO will convene a meeting in Portugal on 23 and 24 June to discuss the risk of the disease and assess countries' preparedness.

When asked whether WHO was confident that Georgia and the Russian Federation could respond to the threat of the virus, Nedret Emiroglu, director of communicable diseases and health security at WHO's European office, said that WHO had a "longstanding relationship" with the countries because of malaria control. She added that the meeting in June would include one to one discussions with these countries and that their plans would be assessed. 